\title{
Understanding Practice Patterns of COPD: A Survey of Physicians in Nepal, Sri Lanka and Malaysia
}

\author{
Ramesh Chokhani · Abdul Razak Muttalif · Kirthi Gunasekera • \\ Aniruddha Mukhopadhyay · Vaibhav Gaur (D) · Jaideep Gogtay
}

Received: February 7, 2021 / Accepted: March 12, 2021 / Published online: April 15, 2021

(c) The Author(s) 2021

\section{ABSTRACT}

Introduction: There is much recent data from Nepal, Sri Lanka and Malaysia that can help us understand the practice patterns of physicians regarding the diagnosis and management of chronic obstructive pulmonary disease (COPD) in these countries. We conducted this survey to understand the practice patterns of physicians related to the diagnosis and management of COPD in these three countries.

Methods: This questionnaire-based, observational, multicentre, cross-sectional survey was carried out with 438 randomly selected physicians consulting COPD patients.

Results: In the survey, $73.29 \%$ of the physicians consulted at least five COPD patients daily (all patients $>40$ years of age). $31.14 \%$ of the COPD patients visiting their doctors were

Supplementary Information The online version contains supplementary material available at https:// doi.org/10.1007/s41030-021-00153-w.

R. Chokhani

Norvic International Hospital, Kathmandu, Nepal

A. R. Muttalif

MAHSA University, Selangor, Malaysia

K. Gunasekera

Nawaloka Hospital, Colombo, Sri Lanka

A. Mukhopadhyay · V. Gaur $(\bowtie) \cdot$ J. Gogtay Global Medical Affairs, Cipla Ltd, Mumbai, India e-mail: vaibhav.gaur@cipla.com women. Among physicians, 95.12\% reported that at least $70 \%$ of their patients were smokers. $34.18 \%$ of the physicians did not routinely use spirometry to diagnose COPD. Most physicians preferred a short-acting $\beta_{2}$-agonist (SABA) $(28.19 \%)$ in the Global Initiative for Chronic Obstructive Lung Disease (GOLD) Group-A and long-acting muscarinic receptor antagonist plus long-acting $\beta_{2}$-agonist/inhaled corticosteroids (LAMA + LABA/ICS) in both the GOLD GroupC (39.86\%) and Group-D (72.89\%) patients. A significant number $(40.67 \%)$ of physicians preferred LABA/LAMA for their GOLD Group-B patients. A pressurised metered dose inhaler (pMDI) with or without spacer was the most preferred device. Only $23.67 \%$ of the physicians believed that at least $70 \%$ of their patients had good adherence $(>80 \%)$ to therapy. Up to $54.42 \%$ of the physicians prescribed inhalation therapy to every COPD patient. Also, 39.95\% of the physicians evaluated their patients' inhalation technique on every visit. Up to $52.67 \%$ of the physicians advised home nebulisation to $>$ $10 \%$ of patients, with nebulised SABA/shortacting muscarinic receptor antagonist (SAMA) being the most preferred management choice. Most physicians offered smoking cessation advice (94.16\%) and/or vaccinations (74.30\%) as non-pharmacological management, whereas pulmonary rehabilitation was offered by a smaller number of physicians. Cost of therapy and poor technique were the most common 
reasons for non-adherence to COPD management therapy.

Conclusion: Awareness of spirometry can be increased to improve the diagnosis of COPD. Though physicians are following the GOLD strategy recommendations for the pharmacological and non-pharmacological management of COPD, awareness of spirometry could be increased to improve proper diagnosis. Regular device demonstration during each visit can improve the inhalation technique and can possibly increase adherence to treatment.

Keywords: COPD; Obstructive airway disease; Malaysia; Nepal; Sri Lanka; Survey; Physicians; Practice pattern

\section{Key Summary Points}

Despite clear strategies from global bodies for diagnosis and management of COPD, the clinical practice of physicians mostly depends on their understanding of the disease and the local trends and practices. Understanding physician perspectives can help in identifying gaps in their practices, which can in turn lead to improved quality of care to the population.

In this survey conducted in Nepal, Sri Lanka and Malaysia, we found that there are many opportunities to increase the awareness of spirometry to improve the proper diagnosis.

Overall, a high burden of COPD was found among women as well as in non-smokers in Nepal.

Evaluation of the inhalation technique during every visit by the physician or by the supporting staff can improve the inhalation technique, which might lead to better adherence to treatment.

pMDI with or without spacer was found to be the most preferred inhalation device.

\section{DIGITAL FEATURES}

This article is published with digital features, including a summary slide, to facilitate understanding of the article. To view digital features for this article go to https://doi.org/10.6084/ m9.figshare.14192120.

\section{INTRODUCTION}

Chronic obstructive pulmonary disease (COPD) is a disease that poses several challenges across the globe, from diagnosis to management. COPD is currently the third leading cause of death worldwide [14]. Globally, an estimated 384 million people suffer from COPD, with the prevalence being $11.7 \%$ [1]. The annual mortality due to COPD is 3 million [28], which may increase to 5.4 million by 2060 [14, 27, 42]. With the increasing prevalence of smoking in developing countries and the ageing populations in high-income countries, the prevalence of COPD is expected to rise over the next 40 years [14, 27, 42]. Similar trends are seen in the Asia-Pacific region $(6.3 \%)$ [15].

The Global Initiative for Chronic Obstructive Lung Disease (GOLD) guideline provides clear guidance pertaining to the diagnosis of COPD and suggests specific diagnostic tools such as history-taking and spirometry. The guideline also suggests pharmacologic treatments, which should be complemented by appropriate non-pharmacologic interventions for effective COPD management [14]. Further, to achieve a better outcome from COPD management, the importance of good device usage techniques $[18,29]$ and adherence $[23,31]$ to treatment are equally important. However, the clinical practice of physicians mostly depends on the their understanding of the disease and the local trends and practices $[24,33]$. Understanding physician perspectives can help in identifying gaps in their practices, which can in turn lead to improved quality of care provided to the patients. 
Moreover, in real-world practice, there is vast diversity in the diagnostic and treatment approaches among physicians in the way the disease is managed in different parts of the world [30]. In the Asia-Pacific region, we found that there was a paucity of recent data from Nepal, Sri Lanka and Malaysia that could help us understand the practice patterns of physicians regarding the diagnosis and management of COPD in these countries. This study aimed to assess the practice patterns with respect to COPD among the participating physicians from these three countries. We attempted to capture attitudes and beliefs related to the diagnosis and monitoring, management, device usage and treatment adherence among their patients with COPD. This study has also tried to describe the core results gathered from the total population of participating physicians, which may or may not be the reflection of results from the total population of physicians in the respective countries.

\section{METHODS}

This was a questionnaire-supported, observation-based, cross-sectional, multicentre, multispecialty survey conducted among physicians from Nepal, Sri Lanka, and Malaysia, who routinely treat patients with COPD. A total of 438 physicians from different specialties participated in the survey [Nepal-171 (135 locations; 45 cities/towns); Sri Lanka-131 (31 cities; 9 provinces); Malaysia-136 (10 states)]. We conducted purposive sampling for the selection of doctors who had respiratory practice and treated a good number of patients with COPD. No sample size calculation was performed for the study.

The principal investigators were chosen from each country, and they helped develop the survey questionnaire (Fig. 1) and reviewed the survey protocol and consent procedures to ensure confidentiality and data safety. The qualified physicians, who were from different cities and towns of the three countries surveyed, were randomly chosen for the survey. They were from different practice settings such as government hospitals, private hospitals, academic institutions or private clinics. The survey questionnaire was not anonymous, and basic details of the participants were collected. All survey forms were hand-filled by the participating physicians and duly undersigned. They also signed the data-sharing consent form, allowing data from the survey to be used for publication if needed. Cipla personnel present in all three countries helped in the distribution of the survey questionnaire form to the participating physicians and then collected the completed sheets from them. Each country took an average of 2 months to complete the data collection. Any reports related to the safety of COPD management therapy in patients were not recorded, as it was understood that this was not applicable because the aim of this survey was to evaluate the opinions of the physicians regarding their COPD patients.

No data specific to any single patient were collected, and there was no intervention involved during the survey conducted. This study does not required ethics approval.

\section{Questionnaire}

The survey questionnaire consisted of 18 closedended questions, wherein some questions required a single answer while others offered multiple-choice answers. The questionnaire was designed to understand the diagnosis and monitoring of COPD, its management, preferences regarding inhalation therapy, types of devices used by patients, and perceptions regarding patient adherence to therapy. We

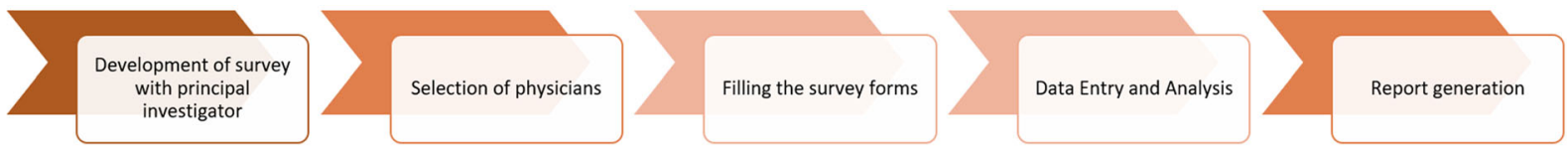

Fig. 1 Scheme depicting the execution of the survey 
Table 1 Frequency distribution of responses of the physicians

\begin{tabular}{|c|c|c|c|c|}
\hline & Total, $n(\%)$ & Nepal, $n(\%)$ & Sri Lanka, $n(\%)$ & Malaysia, $n(\%)$ \\
\hline \multicolumn{5}{|c|}{ (A) How many patients do you encounter with COPD in your daily practice? } \\
\hline Total number of responses & 438 & 171 & 131 & 136 \\
\hline$<5$ & $117(26.71)$ & $31(18.13)$ & $51(38.93)$ & $35(25.74)$ \\
\hline $5-10$ & $199(45.43)$ & $87(50.88)$ & $52(39.69)$ & $60(44.12)$ \\
\hline $10-20$ & $69(15.75)$ & $29(16.96)$ & $15(11.45)$ & $25(18.38)$ \\
\hline$>20$ & $53(12.10)$ & $24(14.04)$ & $13(9.92)$ & $16(11.76)$ \\
\hline \multicolumn{5}{|c|}{ (B) The highest number of your COPD patients belong to which age group? } \\
\hline Total number of responses & 435 & 169 & 130 & 136 \\
\hline$<40$ years & $6(1.38)$ & $0(0)$ & $3(2.31)$ & $3(2.21)$ \\
\hline $40-60$ years & $196(45.06)$ & $84(49.70)$ & $54(41.54)$ & $58(42.65)$ \\
\hline$>60$ years & $233(53.56)$ & $85(50.30)$ & $73(56.15)$ & $75(55.15)$ \\
\hline \multicolumn{5}{|c|}{ (C) What percentage of your COPD patients are female? } \\
\hline Mean percentage & $399(1.14)$ & $156(7.18)$ & $117(2.84)$ & $126(8.99)$ \\
\hline \multicolumn{5}{|c|}{ (D) Which of the following do you prioritise while selecting a treatment for patients with COPD? } \\
\hline Total number of responses & 409 & 158 & 123 & 128 \\
\hline Exacerbation history & $147(35.94)$ & $47(29.75)$ & $32(26.02)$ & $68(53.13)$ \\
\hline Lung function & $66(16.14)$ & $39(24.68)$ & $12(9.76)$ & $15(11.72)$ \\
\hline Symptoms & $196(47.92)$ & $72(45.57)$ & $79(64.23)$ & $45(35.16)$ \\
\hline
\end{tabular}

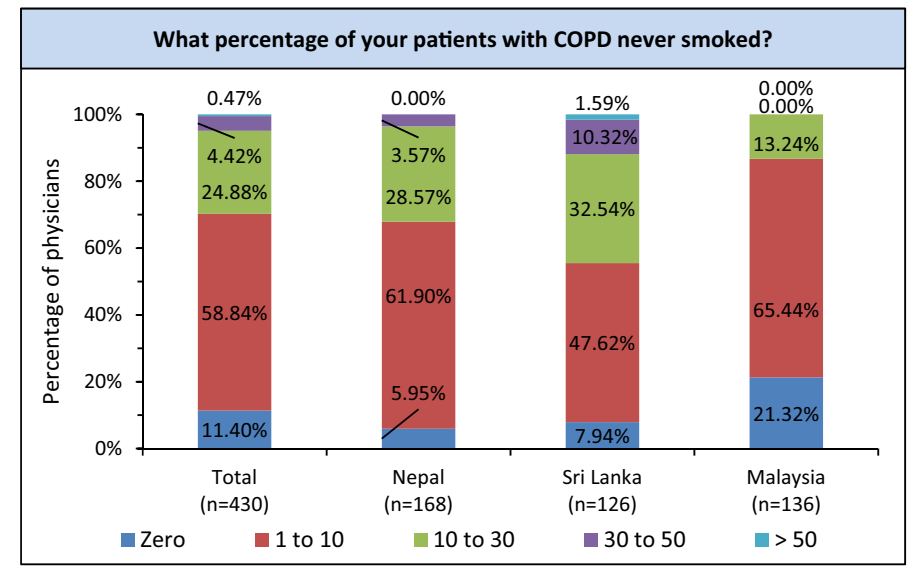

Fig. 2 Percentage of non-smoker COPD patients 


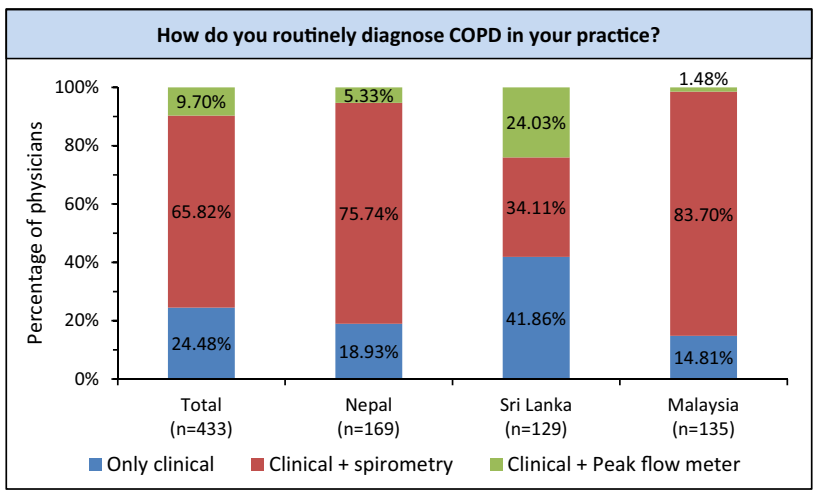

Fig. 3 Method of diagnosing COPD patients in daily practice

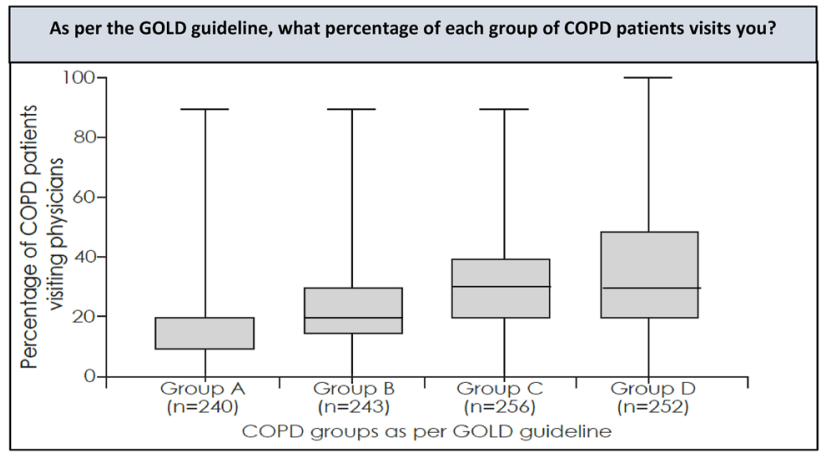

Fig. 4 Percentage of COPD patients by various GOLD groups

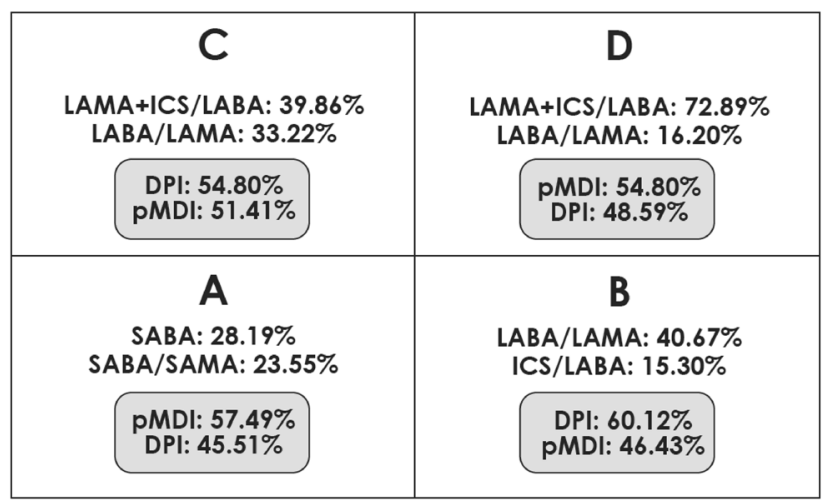

Fig. 5 Preferred therapeutic and device choices of physicians for each group of COPD patients

considered a value of $>80 \%$ as a measure of good adherence among the COPD patients.

\section{Data Collection and Analysis}

The completed survey forms were sent for data entry and statistical analysis to the Chest
Research Foundation (CRF) based in Pune, India. The summarised physician responses were presented as unadjusted means, medians, descriptive statistics, frequency distribution and/or proportions. Due to the disproportionate sample size of each country, the total data were represented in percentages. Among the 


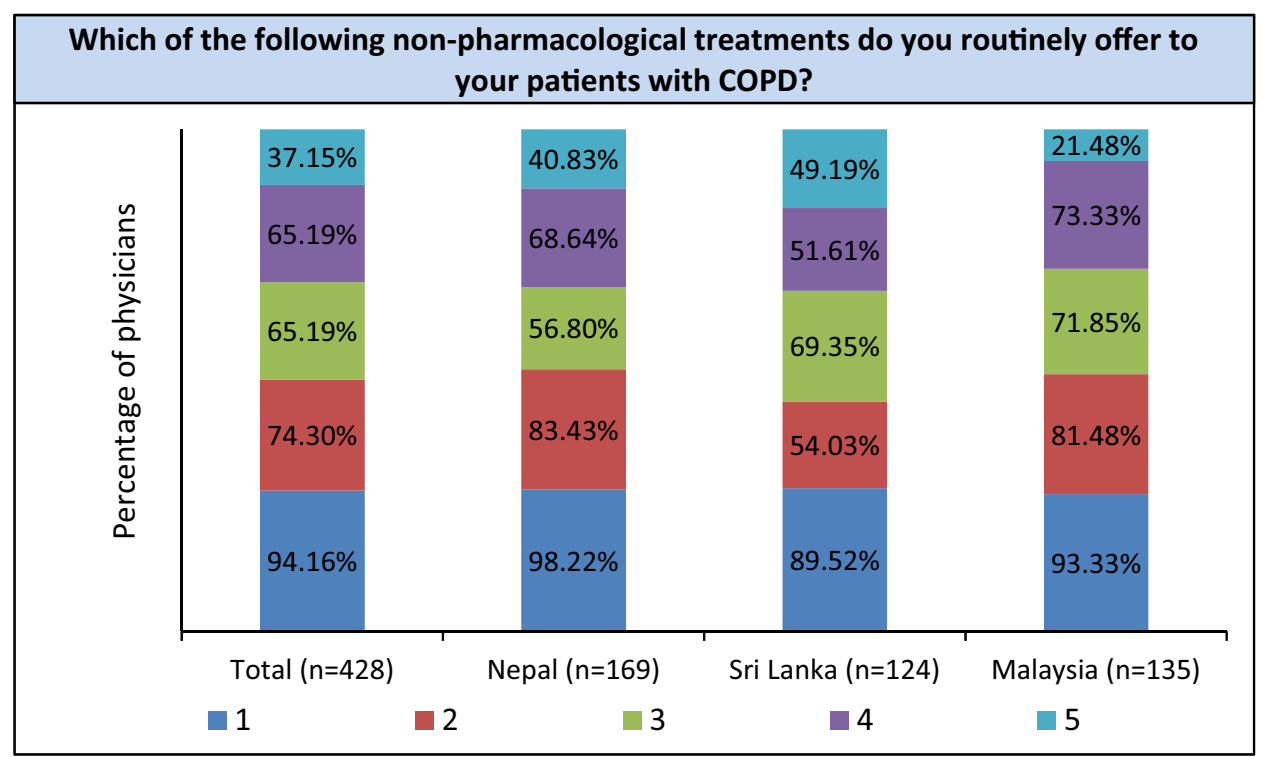

1 - Smoking cessation advice; 2 - Vaccination (influenza, pneumococcal); 3 - Advice for comorbidities (cardiac diseases, diabetes, depression, anxiety, osteoporosis); 4 - Pulmonary rehabilitation/physical exercise schedule; 5 - Dietetic advice

Fig. 6 Non-pharmacological treatments offered by physicians to their patients with COPD

\begin{tabular}{|r|c|c|c|}
\hline \multicolumn{5}{|c|}{ Of the following devices, which one do you prefer to prescribe to maximum patients } \\
with COPD?
\end{tabular}

Fig. 7 Devices preferred by physicians for prescription to the maximum number of their COPD patients

group of responders from each country, there was a group of variable non-responders to different questions in the questionnaire. They were considered as null. The chi-square statistic was applied to understand the difference between the countries in some of the parameters. The entire data analysis was performed using SPSS version 2.2 statistical software, supported by the CRF.

\section{RESULTS}

Out of the 438 physicians surveyed from the three countries, $65.79 \%$ of physicians practised only in hospitals, $18.42 \%$ of physicians had only private practices, and $15.79 \%$ practised in both private and hospital settings. The mean practice tenure of the responders was $>8$ years (range: $<1$ year to 37 years). The total number of participating physicians included consulting 
Table 2 Frequency distribution of responses of the physicians for the questions on inhalation devices (A and B) and factors considered before prescribing any treatment $(\mathrm{C})$

\begin{tabular}{|c|c|c|c|c|}
\hline & Total, $n(\%)$ & Nepal, $n(\%)$ & Sri Lanka, $n(\%)$ & Malaysia, $n(\%)$ \\
\hline \multicolumn{5}{|c|}{ (A) Do you generally prescribe spacer along with pMDI for COPD? } \\
\hline Total number of responses & 424 & 164 & 125 & 135 \\
\hline Yes & $226(53.30)$ & $88(53.66)$ & $87(69.60)$ & $51(37.78)$ \\
\hline No & $198(46.70)$ & $76(46.34)$ & $38(30.40)$ & $84(62.22)$ \\
\hline \multicolumn{5}{|c|}{$\begin{array}{l}\text { (B) How often do you/your assistant/other healthcare professional evaluate the inhalation technique of your COPD } \\
\text { patients? }\end{array}$} \\
\hline Total number of responses & 428 & 166 & 126 & 136 \\
\hline Every visit & $171(39.95)$ & $69(41.57)$ & $33(26.19)$ & $69(50.74)$ \\
\hline Sometimes on suspecting wrong technique & $230(53.74)$ & $88(53.01)$ & $75(59.52)$ & $67(49.26)$ \\
\hline Sometimes as a routine checkup & $26(6.07)$ & $9(5.42)$ & $17(13.49)$ & $0(0)$ \\
\hline Never & $1(0.23)$ & $0(0)$ & $1(0.79)$ & $0(0)$ \\
\hline \multicolumn{5}{|c|}{ (C) Once the category of drug is finalised, what would you consider the most before prescribing? } \\
\hline Total number of responses & 406 & 154 & 120 & 132 \\
\hline Cost of treatment per day & $153(37.68)$ & $69(44.81)$ & $46(38.33)$ & $38(28.79)$ \\
\hline Frequency of daily dose (once or twice daily) & $165(40.64)$ & $54(35.06)$ & $17(14.17)$ & $94(71.21)$ \\
\hline Device type (pMDI or DPI) & $88(21.67)$ & $31(20.13)$ & $57(47.50)$ & $0(0)$ \\
\hline
\end{tabular}

pulmonologists $(17.35 \%)$, internal medicine physicians with a respiratory practice $(47.49 \%)$, and general practitioners (GPs) (35.16\%).

Overall, in their daily practice, $26.71 \%$ of physicians consulted with fewer than 5 COPD patients, $45.43 \%$ consulted with 5-10 patients, $15.75 \%$ consulted with $10-20$ patients, and $12.10 \%$ of physicians consulted with more than 20 COPD patients.

Up to $98.62 \%$ of physicians reported that all the COPD patients who visited them for consultation were $\geq 40$ years of age, among which more than half of the physicians consulted with patients $\geq 60$ years of age. Overall, $31.14 \%$ of the COPD patients who visited their physicians for treatment were women. Specifically, physicians in Nepal reported the highest number of female COPD patients (47.18\%) (Table 1 ).

Up to $95.12 \%$ of physicians found that at least $70 \%$ of their patients with COPD were smokers (Fig. 2). Up to $65.82 \%$ of physicians confirmed that a combination of their clinical expertise and spirometry results gave them the best diagnosis of COPD. This percentage was highest $(83.70 \%)$ in Malaysia. On the other hand, around $65.89 \%$ of physicians in Sri Lanka used their clinical expertise and/or a peak flow meter for diagnosing their patients with COPD (Fig. 3). Collectively from all three countries, $86.67 \%$ of pulmonologists, $70.05 \%$ of physicians and $49.67 \%$ of GPs used spirometry along with patient history for the diagnosis of COPD. Thirty-seven percent of GPs relied only on clinical features for diagnosis.

The diagnosed COPD patients were usually asked to do a follow-up visit every 3 months by their respective physicians (62.50\%). However, in Sri Lanka, most physicians (77.34\%) preferred to call their patients every month for follow-up. For selecting treatment options, 


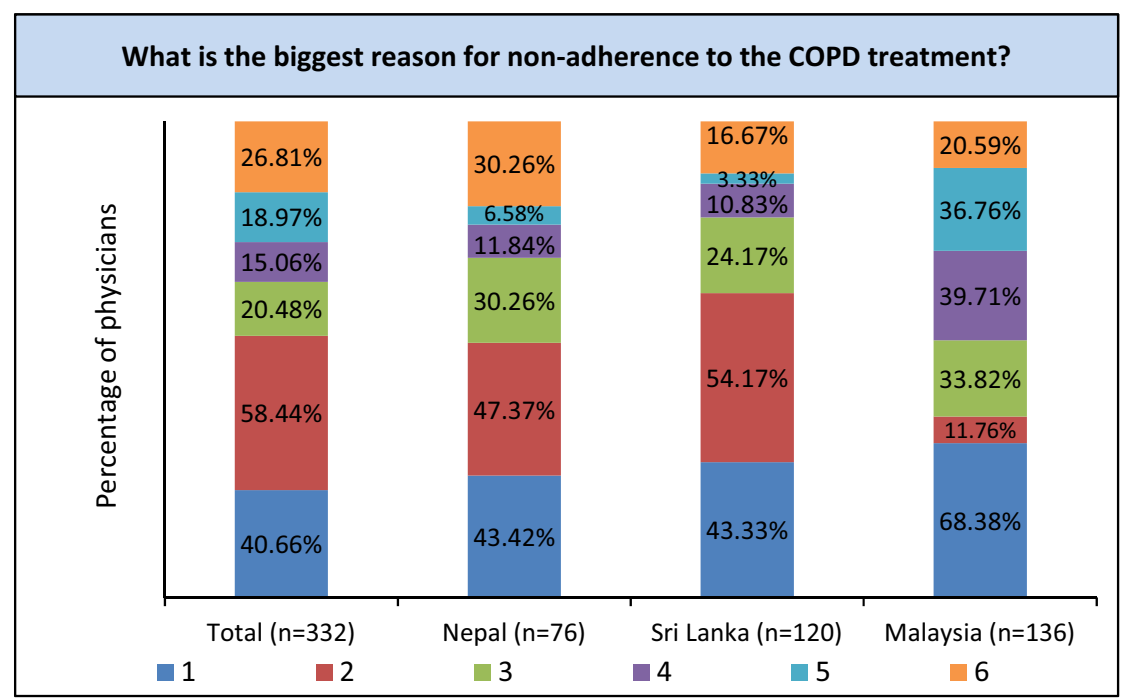

1 - Poor technique; 2 - Cost of therapy; 3 - Patient feels that he/she is perfectly fine and doesn't need the treatment; 4 - Patient feels that the treatment is ineffective; 5 - Device type; 6 - Apprehension regarding the inhalation therapy

Fig. 8 Biggest reason for non-adherence to COPD treatment

$47.92 \%$ of physicians prioritised the assessing of the patient's symptoms for the disease. The remaining $35.94 \%$ and $16.14 \%$ of physicians prioritised the patient's exacerbation history and lung function, respectively. However, more than half of the physicians (53.13\%) in Malaysia prioritised exacerbation history, while in Sri Lanka, $64.23 \%$ of physicians prioritised their patient's symptoms (Table 1 ).

According to the latest GOLD guideline, the physicians confirmed that the median percentage of patients from GOLD groups $\mathrm{A}, \mathrm{B}, \mathrm{C}$ and $\mathrm{D}$ were $10 \%, 20 \%, 30 \%$ and $30 \%$, respectively (Fig. 4). For the GOLD Group-A COPD patients, most physicians preferred a short-acting $\beta_{2}$-agonist (SABA) (28.19\%) followed by a combination of a SABA and a short-acting muscarinic receptor antagonist (SAMA) (23.55\%). Physician preference for GOLD Group-B COPD patients was a long-acting $\beta_{2}$-agonist (LABA) and longacting muscarinic receptor antagonist (LAMA) combination $(40.67 \%)$ followed by a combination of LABA and inhaled corticosteroids (ICS) (15.30\%). LAMA along with an ICS/LABA combination was preferred for both GOLD Group-C (39.86\% of physicians) and GOLD Group-D (72.89\% of physicians), respectively. LABA/ LAMA was preferred by $32.22 \%$ and $16.20 \%$ of physicians for GOLD Group-C and Group-D, respectively. The pressurised metered dose inhalers (pMDIs) and dry powder inhalers (DPIs) were equally preferred by most physicians for all the GOLD groups (Fig. 5).

Non-pharmacological treatments routinely offered by most physicians to their patients with COPD included smoking cessation advice $(94.16 \%)$ and influenza or pneumococcal vaccinations (74.30\%). The least preferred option was dietetic advice (37.15\%), although $49.19 \%$ of physicians in Sri Lanka preferred dietetic advice for their patients with COPD as a routine non-pharmacological treatment option (Fig. 6).

Up to $70 \%$ of physicians preferred to prescribe inhalation therapy to at least $70 \%$ of their COPD patients; in Malaysia and Sri Lanka, $65.93 \%$ and $60.94 \%$ of physicians, respectively, prescribed inhalation therapy to every COPD patient. Of physicians, $93.63 \%$ believed that at least $10 \%$ of their patients were apprehensive about using inhalation therapy.

Overall, $56.55 \%$ of physicians preferred either a pMDI with or without a spacer, whereas $41.99 \%$ of physicians preferred DPIs. In Sri Lanka, $88.10 \%$ of physicians preferred a pMDI with or without spacer, and in Nepal, three out of four physicians preferred DPI devices (Fig. 7). 
Overall, approximately half of the responders agreed that they prefer to add a spacer to their pMDI prescriptions; in Sri Lanka, this proportion was as high as $69.60 \%$.

When asked whether they prescribe home nebulisation to any of their patients with COPD, $85.03 \%, 42.97 \%$ and $22.06 \%$ of physicians from Nepal, Sri Lanka, and Malaysia answered in the affirmative, respectively. The differences were statistically significant $(p<0.01)$. Further, $52.47 \%$ (approximately 61.43\% [Nepal]; 33.96\% [Sri Lanka]; 43.33\% [Malaysia]) of the physicians confirmed that at least $10 \%$ of their COPD patients were prescribed home nebulisation. A combination of nebulised SABA and SAMA was the most preferred drug (by 79.34\%) to be given for nebulisation in Nepal $(80.74 \%)$, Sri Lanka (71.43\%) and Malaysia (86.21\%).

Up to $23.67 \%$ of physicians believed that at least $70 \%$ of their patients had good adherence (> 80\%) to their prescribed inhalation therapy. Only $39.95 \%$ of physicians evaluated their patients' inhalation technique on every visit, whereas $53.74 \%$ of physicians evaluated only when they suspected a wrong technique. However, physician evaluation of the inhalation technique on every visit was high in Malaysia (50.74\%).

Physicians considered frequency of daily dosing (40.64\%) most, followed by cost of treatment per day (37.68\%), before prescribing the decided treatment for their patients. The highest percentage was seen among physicians from Malaysia (71.21\%), who also considered daily dose frequency the most. On the other hand, the physicians from Sri Lanka (47.50\%) affirmed that choosing the right type of device was the most important parameter (Table 2).

Most physicians found the cost of therapy $(58.44 \%)$ as the greatest reason for non-adherence, followed by poor technique (40.66\%) and patient apprehension regarding the inhalation therapy $(26.81 \%)$. Similar non-adherence reasons of poor technique and cost of therapy were chosen by a larger group of physicians from Malaysia (68.38\%) and Sri Lanka (54.17\%), respectively (Fig. 8).

\section{DISCUSSION}

The global burden of COPD is gradually increasing and contributes substantially to overall disability and mortality around the world [14]. Country-level data suggest that COPD has become the fourth leading cause of death in Nepal, eighth in Sri Lanka and tenth in Malaysia [21]. In Nepal in particular, COPD is responsible for $43 \%$ of the non-communicable disease burden and $2.56 \%$ of hospitalisations $[6,21]$. Furthermore, considering about 448,000 cases in Malaysia, the prevalence of moderateto-severe COPD was estimated to be $4.7 \%$ in 2003 [15]. According to a study by Amarasiri et al., the observed overall prevalence of COPD in Sri Lanka in 2017 was 10.5\% [4]. With an objective to learn about the current treatment practices and physicians' perceptions about the disease and the challenges they face, the present survey was conducted in three Asia-Pacific countries, namely, Nepal, Sri Lanka, and Malaysia.

Smoking was considered to be the most common root cause of COPD by physicians, and they often suggested smoking-cessation as a non-pharmacological treatment option in addition to vaccination. Most of the physicians reported that their clinical expertise and the spirometric results helped them in diagnosing their patients. Further, they often prioritised the disease symptoms and exacerbation history of patients for treatment selection. Most physicians preferred to manage their severe COPD patients by adding a combination of ICS/LABA along with LAMA. While choosing the right device for their COPD patients, most physicians relied on pMDIs with or without a spacer. While many of these choices can be attributed to the availability of certain drugs and their combinations in specific inhalation devices, we and many of the doctors in the region believe that there is a high inspiratory flow required to activate the DPI device, which is very difficult for a patient with COPD to generate $[5,7,13]$. For some patients, many physicians preferred home nebulisation with SABA and SAMA combinations. The physicians tried to maintain a good (> 80\%) adherence level for their patients 
by evaluating their inhalation techniques at every visit. Many physicians felt that poor technique and per-day cost of treatment could be the reasons for patient non-adherence to therapy.

The global trend suggests that COPD in women is uncommon; however, women are found to be more susceptible to COPD than men [37]. Additionally, the early onset of smoking among women may have a greater harmful impact on forced expiratory volume in $1 \mathrm{~s}\left(\mathrm{FEV}_{1}\right)$, as their lungs are smaller than those of men [26]. In the present study, 31.14\% of patients with COPD were women; the number was as high as $47.18 \%$ in Nepal. According to the World Health Organization (WHO), the prevalence of smoking is $56.5 \%$ in men and $19.5 \%$ in women. However, the prevalence of COPD appears to be higher among Nepali women than men $[2,3]$. These high numbers from Nepal could be attributed to the fact that, in Nepal, more than $85 \%$ of households (98\% in rural areas) are rural dwellers and still rely on biomass fuel. Thus, they are most susceptible to COPD due to their cooking habits in poorly ventilated kitchens, which leads to high-level exposure to particulate matter at home [2]. Ghaffar et al. found that in South Asian countries, including Nepal, poorer people burn wood as fuel in their homes, especially in winter, which may likely increase the indoor air pollution and contribute to the burden of COPD [12]. These results are in line with the results published from Nepal and Sri Lanka that suggest a significant burden of COPD in the non-smoker population $[2,9,16]$.

The present survey also showed that $95.12 \%$ of physicians observed that up to $30 \%$ of their patients with COPD were non-smokers. This is in line with the global trend showing that an estimated $25-45 \%$ of patients with COPD have never smoked, which also leads to the conclusion that the burden is much higher with nonsmoker COPD [6, 34].

Worldwide, $50-90 \%$ of patients with COPD remain undiagnosed, which suggests a burden on the health services along with significant morbidity $[11,20]$. Under- or over-diagnosis also remains a global problem contributing to the overall COPD burden. The common reason for under-diagnosis could be the lack of availability or accessibility of a spirometer, mostly in rural areas [10]. Over-diagnosis, on the other hand, may occur in patients with a history of exposure to noxious particles and/or who suffer from comorbidities such as asthma or post-tuberculosis afflictions along with respiratory symptoms [11, 25, 35]. In the present survey, it was observed that the physicians in these regions adhered to COPD management according to the GOLD guideline, based on the patient's disease control. Most physicians considered certain parameters after finalising the category of drug for their patients. Acute conditions that were commonly found among COPD patients with exacerbations were usually managed with nebulisation therapy, though in some cases home nebulisation was also recommended by physicians. Non-pharmacological options were complementary to pharmacological treatment options and were considered as part of the overall COPD management strategy.

Spirometry is a crucial preliminary test for the evaluation of patients with respiratory symptoms. A ratio of post-bronchodilator $\mathrm{FEV}_{1}$ to forced vital capacity (FVC) $<0.70$ confirms the presence of COPD [14]. Lack of use of spirometry in the diagnostic assessment of COPD remains a major issue, even though postbronchodilator spirometry is the gold standard for the diagnostic confirmation of COPD [19]. In the present survey, COPD diagnosis was routinely practised by physicians not only using their own clinical expertise or tools such as spirometry, but also by using a peak expiratory flow meter as an option for COPD confirmation. In Sri Lanka, $24.03 \%$ of physicians relied only on their clinical expertise and peak expiratory flow meter testing to confirm COPD diagnosis.

Good adherence is associated with a decreased risk of severe exacerbations and mortality. Lower adherence may lead to a higher rate of mortality [41]. General trends in COPD adherence confirm that lack of adherence in COPD patients is not uncommon and it contributes to a reduction in the quality of life as well as unfavourable health outcomes, which further contribute to an increase in healthcare expenditure [8]. WHO data suggest that in chronic diseases, an average of $50 \%$ of patients 
from developed countries adhere to long-term therapy [44]. The results of the present survey showed that poor technique is one of the prime reasons for non-adherence to COPD treatment in all three countries surveyed; additionally, cost of therapy was also a concern in Nepal and Sri Lanka.

Sometimes patients are unable to understand the instructions about inhalation therapy, causing a rapid decline in their adherence level. The literacy rate in some countries may play a major role in this decline. For example, according to World Bank data (2018), in Nepal, the literacy rate among adults aged $\geq 15$ years was $68 \%$ compared with that of Sri Lanka (92\%) or Malaysia (95\%) [45]. A recent study from Nepal concluded that patients with inadequate health literacy knew significantly less about the disease or condition than patients with adequate health literacy [36]. This is in line with our results showing that a larger number of doctors from Nepal (30.26\%) believe that their patients are apprehensive about inhalation therapy compared with doctors from the other two countries.

Cost of medication is higher in adherent patients compared with non-adherent patients. In contrast, the overall hospitalisation cost is always higher in non-adherent patients compared with adherent patients [17, 38-40]. The survey physicians believe that the cost of therapy is the biggest reason for non-adherence. This is further supported by WHO data that confirms that the total expenditure on health per capita is $5.8 \%$ in Nepal, which is high compared with Sri Lanka and Malaysia [43]. This can sometimes decrease the adherence level among patients who are unwilling and/or unable to purchase and continue their longterm inhalation therapy for a chronic disease such as COPD.

\section{Limitations}

There were a few limitations in this study. Since only three Asia-Pacific countries were selected to gather the data, the findings of this study cannot be generalised. However, the outcomes of the study provide vital information for future strategies. Worldwide, in many countries, COPD is a disease that is mostly managed by pulmonologists. Nevertheless, in countries such as Nepal and Sri Lanka, pulmonologists are comparatively few in number. Hence, physicians and general practitioners also practice respiratory therapy and treat COPD patients. Therefore, we included them in the survey along with pulmonologists. In the future, a specialty-based analysis may give a more focussed picture of the practice patterns in these countries. In the future, additional surveys designed to assess COPD patients in Nepal, Sri Lanka and Malaysia can highlight further directions on effective COPD management from the patient perspective. In our study, we found that approximately two-third of the participating doctors are recommending a pulmonary rehabilitation (PR)/physical exercise schedule to their patients. This number recommending PR for COPD patients seems to be very high when we compare it to any other place in the world, even in countries with advanced healthcare services such as those in Europe and the United Kingdom [22, 32]. This can be attributed to the formulation of the question, where even a physical exercise schedule is considered along with pulmonary rehabilitation. This can surely be addressed in future surveys that are more focused on PR.

\section{CONCLUSION}

In this survey conducted in Nepal, Sri Lanka and Malaysia, we found that physicians are mostly following the GOLD strategy recommendations for the pharmacological and nonpharmacological management of COPD. The study demonstrated that there are many opportunities to increase awareness of spirometry to enable better diagnosis. Overall, a high burden of COPD was found among women and among non-smokers in Nepal. Evaluation of the inhalation technique during every visit by the physician or by the supporting staff can improve the inhalation technique, which might lead to better adherence to treatment. A pMDI with or without a spacer was found to be the most preferred inhalation device. We hope that 
the insights provided herein will help in designing more pragmatic solutions to improve the COPD management status in these three Asia-Pacific countries.

\section{ACKNOWLEDGEMENTS}

We thank all the participating physicians for their time and valuable contribution to this study. We also thank the Cipla field force from Nepal, Sri Lanka and Malaysia. Authors also acknowledge Ms Sapna Madas, the biostatistician at Chest Research Foundation (currently Director and Head, Data Management and Statistics Chest Research and Training Pvt. Ltd., Pune, India) for her support for data entry and compilation.

Funding. This study was supported by Cipla Ltd. The journal's Rapid Service Fee was supported by Cipla Ltd.

Authorship. All named authors meet the International Committee of Medical Journal Editors (ICMJE) criteria for authorship for this article, take responsibility for the integrity of the work as a whole, and have given their approval for this version to be published.

Disclosures. Mr Aniruddha Mukhopadhyay, Dr Vaibhav Gaur and Dr Jaideep Gogtay are permanent employees of Cipla Ltd. Dr Ramesh Chokhani, Dr Abdul Razak Muttalif and Dr Kirthi Gunasekera has nothing to disclose related this survey. No honorarium was given to any of the authors or any participant for conducting or participating in this study. The authors alone are responsible for the content and writing of the paper.

Compliance with Ethics Guidelines. No data specific to any single patient were collected and there was no intervention involved during the survey conducted. This study does not require any ethics approval.

Data Availability. The data sets generated and/or analysed during the current study are available from the corresponding author on reasonable request.

Open Access. This article is licensed under a Creative Commons Attribution-NonCommercial 4.0 International License, which permits any non-commercial use, sharing, adaptation, distribution and reproduction in any medium or format, as long as you give appropriate credit to the original author(s) and the source, provide a link to the Creative Commons licence, and indicate if changes were made. The images or other third party material in this article are included in the article's Creative Commons licence, unless indicated otherwise in a credit line to the material. If material is not included in the article's Creative Commons licence and your intended use is not permitted by statutory regulation or exceeds the permitted use, you will need to obtain permission directly from the copyright holder. To view a copy of this licence, visit http://creativecommons.org/licenses/by$\mathrm{nc} / 4.0 /$.

\section{REFERENCES}

1. Adeloye D, Chua S, Lee C, Basquill C, Papana A, Theodoratou E, Nair H, Gasevic D, Sridhar D, Campbell H, Chan KY, Sheikh A, Rudan I, (GHERG). Global and regional estimates of COPD prevalence: systematic review and meta-analysis. J Glob Health. 2015;5(2):20415. https://doi.org/10. 7189/jogh.05-020415.

2. Adhikari TB, Acharya P, Högman M, Neupane D, Karki A, Drews A, Cooper BG, Sigsgaard T, Kallestrup P. Prevalence of chronic obstructive pulmonary disease and its associated factors in Nepal: Findings from a community-based household survey. Int J COPD. 2020;15:2319-31. https://doi.org/ 10.2147/COPD.S268110.

3. Adhikari TB, Neupane D, Kallestrup P. Burden of COPD in Nepal. Int J COPD. 2018;13:583-9. https://doi.org/10.2147/COPD.S154319.

4. Amarasiri L, Gunasinghe W, Sadikeen A, Fernando A, Madegedara D, Wickramasinghe R, Gunasekera K. The prevalence of chronic obstructive pulmonary disease (COPD) in Sri Lanka:outcome of the BOLD study. Eur Respir J. 2017;50(suppl 61): PA1212. https://doi.org/10.1183/1393003.congress2017.PA1212. 
5. Baral MA. Knowledge and practice of dry powder inhalation among patients with chronic obstructive pulmonary disease in a regional hospital, Nepal. Int J Gen Med. 2019;12:31-7. https://doi.org/10.2147/ IJGM.S165659.

6. Bhandari R, Sharma R. Epidemiology of chronic obstructive pulmonary disease: a descriptive study in the mid-western region of Nepal. Int J Chron Obstruct Pulmon Dis. 2012;7:253-7. https://doi. org/10.2147/copd.s28602.

7. Chen SY, Huang CK, Peng HC, Yu CJ, Chien JY. Inappropriate peak inspiratory flow rate with dry powder inhaler in chronic obstructive pulmonary disease. Sci Rep. 2020;10(1):1-9. https://doi.org/10. 1038/s41598-020-64235-6.

8. DiMatteo MR. Variations in patients' adherence to medical recommendations: a quantitative review of 50 years of research. Med Care. 2004;42(3):200-9. https://doi.org/10.1097/01.mlr.0000114908.90348. f9.

9. Gautam R, Neupane D, Karki A, Kallestrup P. Community-based management of COPD in Nepal. Lancet Respir Med. 2017;5(1):e6. https://doi.org/10. 1016/S2213-2600(16)30431-3.

10. Gershon AS, Guan J, Victor JC, Goldstein R, To T. Quantifying health services use for chronic obstructive pulmonary disease. Am J Respir Crit Care Med. 2013;187(6):596-601. https://doi.org/10. 1164/rccm.201211-2044OC.

11. Gershon AS, Hwee J, Chapman KR, Aaron SD, O'Donnell DE, Stanbrook MB, Bourbeau J, Tan W, $\mathrm{Su}$ J, Victor JC, To T. Factors associated with undiagnosed and overdiagnosed COPD. Eur Respir J. 2016;48:561-4. https://doi.org/10.1183/13993003. 00458-2016.

12. Ghaffar A, Reddy KS, Singhi M. Burden of noncommunicable diseases in South Asia. BMJ. 2004;328(7443):807-10. https://doi.org/10.1136/ bmj.328.7443.807.

13. Ghosh S, Pleasants RA, Ohar JA, Donohue JF, Drummond MB. Prevalence and factors associated with suboptimal peak inspiratory flow rates in COPD. Int J COPD. 2019;14:585-95. https://doi. org/10.2147/COPD.S195438.

14. Global Initiative for Chronic Obstructive Lung Disease (GOLD) 2021. https://goldcopd.org/wpcontent/uploads/2020/11/GOLD-REPORT-2021-v1. 1-25Nov20_WMV.pdf.

15. Regional COPD Working Group. COPD prevalence in 12 Asia-Pacific countries and regions: projections based on the COPD prevalence estimation model.
Respirology. 2003;8(2):192-8. https://doi.org/10. 1046/j.1440-1843.2003.00460.x.

16. Gunasekera KD, Amarasiri DL, Fernando A, Wickramasinghe $\mathrm{R}$. Chronic obstructive pulmonary disease (COPD) in non-smoking Sri Lankan adults. Eur Respir J. 2019;54(suppl 63):PA2838. https://doi.org/ 10.1183/13993003.congress-2019.pa2838.

17. Halpern R, Baker CL, Su J, Woodruff KB, PauloseRam R, Porter V, Shah H. Outcomes associated with initiation of tiotropium or fluticasone/salmeterol in patients with chronic obstructive pulmonary disease. Patient Prefer Adherence. 2011;5:375-88. https://doi.org/10.2147/ppa.s19991.

18. Hanania NA, Braman S, Adams SG, Adewuya R, Ari A, Brooks J, Mahler DA, Ohar JA, Peters J, Sanjar S. The role of inhalation delivery devices in COPD: perspectives of patients and health care providers. Chronic Obstr Pulm Dis. 2018;5(2):111-23. https:// doi.org/10.15326/jcopdf.5.2.2017.0168.

19. Hangaard S, Helle T, Nielsen C, Hejlesen OK. Causes of misdiagnosis of chronic obstructive pulmonary disease: a systematic scoping review. Respir Med. 2017;129:63-84. https://doi.org/10.1016/j.rmed. 2017.05.015.

20. Haroon S, Adab P, Riley RD, Fitzmaurice D, Jordan RE. Predicting risk of undiagnosed COPD: development and validation of the TargetCOPD score. Eur Respir J. 2017. https://doi.org/10.1183/ 13993003.02191-2016.

21. Hay SI, Abajobir AA, Abate KH, Abbafati C, Abbas KM, Abd-Allah F, Abdulle AM, Abebo TA, Abera SF, Aboyans V, Abu-Raddad LJ, Ackerman IN, Adedeji IA, Adetokunboh O, Afshin A, Aggarwal R, Agrawal S, Agrawal A, Kiadaliri AA, Bryane CEG, et al. Global, regional, and national disability-adjusted lifeyears (DALYs) for 333 diseases and injuries and healthy life expectancy (HALE) for 195 countries and territories, 1990-2016: A systematic analysis for the Global Burden of Disease Study 2016. Lancet. 2017;390(10100):1260-344. https://doi.org/10. 1016/S0140-6736(17)32130-X.

22. Hogg L, Garrod R, Thornton H, McDonnell L, Bellas $\mathrm{H}$, White P. Effectiveness, attendance, and completion of an integrated, system-wide pulmonary rehabilitation service for COPD: prospective observational study. COPD J Chronic Obstruct Pulm Dis. 2012;9(5):546-54. https://doi.org/10.3109/ 15412555.2012 .707258 .

23. Jardim JR, Nascimento OA. The importance of inhaler adherence to prevent COPD exacerbations. Med Sci (Basel). 2019. https://doi.org/10.3390/ medsci7040054. 
24. Kelly MG, Elborn JS, Society BT. Admissions with chronic obstructive pulmonary disease after publication of national guidelines. Ir J Med Sci. 2002;171(1):16-9. https://doi.org/10.1007/ BF03168933.

25. Lam KB, Jiang CQ, Jordan RE, Miller MR, Zhang WS, Cheng KK, Lam TH, Adab P. Prior TB, smoking, and airflow obstruction: a cross-sectional analysis of the Guangzhou Biobank Cohort Study. Chest. 2010;137(3):593-600. https://doi.org/10.1378/ chest.09-1435.

26. Langhammer A, Johnsen R, Gulsvik A, Holmen TL, Bjermer L. Sex differences in lung vulnerability to tobacco smoking. Eur Respir J. 2003;21(6):1017-23. https://doi.org/10.1183/09031936.03.00053202.

27. Lopez AD, Shibuya K, Rao C, Mathers CD, Hansell AL, Held LS, Schmid V, Buist S. Chronic obstructive pulmonary disease: current burden and future projections. Eur Respir J. 2006;27(2):397-412. https:// doi.org/10.1183/09031936.06.00025805.

28. Naghavi M, Wang H, Lozano R, Davis A, Liang X, Zhou M, Vollset SE, Abbasoglu Ozgoren A, Abdalla S, Abd-Allah F, Abdel Aziz MI, Abera SF, Aboyans V, Abraham B, Abraham JP, Abuabara KE, Abubakar I, Abu-Raddad LJ, Abu-Rmeileh NME, Temesgen AM, et al. Global, regional, and national age-sex specific all-cause and cause-specific mortality for 240 causes of death, 1990-2013: a systematic analysis for the Global Burden of Disease Study 2013. Lancet. 2015;385(9963):117-71. https://doi.org/10.1016/ S0140-6736(14)61682-2.

29. Pothirat C, Chaiwong W, Phetsuk N, Pisalthanapuna S, Chetsadaphan N, Choomuang W. Evaluating inhaler use technique in COPD patients. Int J Chron Obstruct Pulmon Dis. 2015;10:1291-8. https://doi.org/10.2147/COPD.S85681.

30. Ragaišienè G, Kibarskytė R, Gauronskaitė R, Giedraitytė M, Dapšauskaitė A, Kasiulevičius V, Danila E. Diagnosing COPD in primary care: what has real life practice got to do with guidelines? Multidiscip Respir Med. 2019;14:28. https://doi. org/10.1186/s40248-019-0191-6.

31. Restrepo RD, Alvarez MT, Wittnebel LD, Sorenson H, Wettstein R, Vines DL, Sikkema-Ortiz J, Gardner DD, Wilkins RL. Medication adherence issues in patients treated for COPD. Int J Chron Obstruct Pulmon Dis. 2008;3(3):371-84. https://doi.org/10. 2147/copd.s3036.

32. Rochester CL, Vogiatzis I, Holland AE, Lareau SC, Marciniuk DD, Puhan MA, Spruit MA, Masefield S, Casaburi R, Clini EM, Crouch R, Garcia-Aymerich J, Garvey C, Goldstein RS, Hill K, Morgan M, Nici L, Pitta F, Ries AL, Stahlberg B, et al. An official American Thoracic Society/European Respiratory
Society policy statement: enhancing implementation, use, and delivery of pulmonary rehabilitation. Am J Respir Crit Care Med. 2015;192(11):1373-86. https://doi.org/10.1164/rccm.201510-1966ST.

33. Rutschmann OT, Janssens JP, Vermeulen B, Sarasin FP. Knowledge of guidelines for the management of COPD: a survey of primary care physicians. Respir Med. 2004;98(10):932-7. https://doi.org/10.1016/j. rmed.2004.03.018.

34. Salvi SS, Barnes PJ. Chronic obstructive pulmonary disease in non-smokers. Lancet. 2009;374(9691): 733-43. 6736(09)61303-9.

35. Sarkar M, Srinivasa MI, Kumar K. Tuberculosis associated chronic obstructive pulmonary disease. Clin Respir J. 2017;11(3):285-95. https://doi.org/ 10.1111/crj.12621.

36. Shrestha A, Singh SB, Khanal VK, Bhattarai S, Maskey R, Pokharel PK. Health literacy and knowledge of chronic diseases in Nepal. Health Lit Res Pract. 2018;2(4):e221-30. https://doi.org/10.3928/ 24748307-20181025-01.

37. Silverman EK, Chapman HA, Drazen JM, Weiss ST, Rosner B, Campbell EJ, O'Donnell WJ, Reilly JJ, Ginns L, Mentzer S, Wain J, Speizer FE. Genetic epidemiology of severe, early-onset chronic obstructive pulmonary disease. Risk to relatives for airflow obstruction and chronic bronchitis. Am J Respir Crit Care Med. 1998;157(6 Pt 1):1770-8. https://doi.org/10.1164/ajrccm.157.6.9706014.

38. Simoni-Wastila L, Wei YJ, Qian J, Zuckerman IH, Stuart B, Shaffer T, Dalal AA, Bryant-Comstock L. Association of chronic obstructive pulmonary disease maintenance medication adherence with allcause hospitalization and spending in a Medicare population. Am J Geriatr Pharmacother. 2012;10(3):201-10. https://doi.org/10.1016/j. amjopharm.2012.04.002.

39. Toy EL, Beaulieu NU, McHale JM, Welland TR, Plauschinat CA, Swensen A, Duh MS. Treatment of COPD: relationships between daily dosing frequency, adherence, resource use, and costs. Respir Med. 2011;105(3):435-41. https://doi.org/10.1016/ j.rmed.2010.09.006.

40. van Boven JF, Chavannes $\mathrm{NH}$, van der Molen T, Rutten-van Molken MP, Postma MJ, Vegter S. Clinical and economic impact of non-adherence in COPD: a systematic review. Respir Med. 2014;108(1):103-13. https://doi.org/10.1016/j. rmed.2013.08.044.

41. Vestbo J, Anderson JA, Calverley PM, Celli B, Ferguson GT, Jenkins C, Knobil K, Willits LR, Yates JC, Jones PW. Adherence to inhaled therapy, mortality 
and hospital admission in COPD. Thorax. 2009;64(11):939-43. https://doi.org/10.1136/thx. 2009.113662.

42. WHO. Projections of mortality and causes of death, 2016 to 2060. World Health Organization; 2018. http://www.who.int/healthinfo/global_burden_ disease/projections/en/.

43. WHO. Data from Global Health Observatory data repository for Nepal. World Health Organization; 2020. http://www.who.int/countries/npl/en/.
44. WHO. Adherence to long-term therapies: evidence for action. World Health Organization; 2020. https://www.who.int/chp/knowledge/publications/ adherence_report/en/.

45. World Bank. Literacy rate, adult total (\% of people ages 15 and above)-Nepal. 2018. https://data. worldbank.org/indicator/SE.ADT.LITR.

ZS?locations=NP. 